\title{
Alcohol consumption, drinking patterns, and ischemic heart disease: a narrative review of meta-analyses and a systematic review and meta-analysis of the impact of heavy drinking occasions on risk for moderate drinkers
}

Michael Roerecke ${ }^{1 *}$ and Jürgen Rehm ${ }^{1,2,3,4,5}$

\begin{abstract}
Background: Alcohol consumption is a major global risk factor for mortality and morbidity. Much discussion has revolved around the diverse findings on the complex relationship between alcohol consumption and the leading cause of death and disability, ischemic heart disease (IHD).

Methods: We conducted a systematic search of the literature up to August 2014 using Preferred Reporting Items for Systematic Reviews and Meta-Analyses guidelines to identify meta-analyses and observational studies examining the relationship between alcohol drinking, drinking patterns, and IHD risk, in comparison to lifetime abstainers. In a narrative review we have summarized the many meta-analyses published in the last 10 years, discussing the role of confounding and experimental evidence. We also conducted meta-analyses examining episodic heavy drinking among on average moderate drinkers.

Results: The narrative review showed that the use of current abstainers as the reference group leads to systematic bias. With regard to average alcohol consumption in relation to lifetime abstainers, the relationship is clearly J-shaped, supported by short-term experimental evidence and similar associations within strata of potential confounders, except among smokers. Women experience slightly stronger beneficial associations and also a quicker upturn to a detrimental effect at lower levels of average alcohol consumption compared to men. There was no evidence that chronic or episodic heavy drinking confers a beneficial effect on IHD risk. People with alcohol use disorder have an elevated risk of IHD (1.5- to 2-fold). Results from our quantitative meta-analysis showed that drinkers with average intake of $<30 \mathrm{~g} /$ day and no episodic heavy drinking had the lowest $\mathrm{HHD}$ risk (relative risk $=0.64,95 \%$ confidence interval 0.53 to 0.71 ). Drinkers with episodic heavy drinking occasions had a risk similar to lifetime abstainers (relative risk $=1.12,95 \%$ confidence interval 0.91 to 1.37 ).

Conclusions: Epidemiological evidence for a beneficial effect of low alcohol consumption without heavy drinking episodes is strong, corroborated by experimental evidence. However, episodic and chronic heavy drinking do not provide any beneficial effect on IHD. Thus, average alcohol consumption is not sufficient to describe the risk relation between alcohol consumption and IHD. Alcohol policy should try to reduce heavy drinking patterns.
\end{abstract}

Keywords: Alcohol, Binge drinking, Heavy drinking, Ischemic heart disease, Meta-analysis, Systematic review

\footnotetext{
* Correspondence: m.roerecke@web.de

'Social and Epidemiological Research Department, Centre for Addiction and

Mental Health (CAMH), 33 Russell Street, Toronto, Ontario M5S 2S1, Canada

Full list of author information is available at the end of the article
} 


\section{Background}

Ischemic heart disease (IHD) is the leading cause of death and disease burden in the US [1], Europe [2], and globally $[3,4]$, and alcohol consumption is one of the leading risk factors for mortality and morbidity [5,6]. There are wellestablished risks from neuro-toxic, hepato-toxic, and carcinogenic effects caused by alcohol consumption (for example, the risk for cancers of the upper aerodigestive tract [7-9], injuries [6,10], and liver cirrhosis $[6,10,11])$. However, there has been much debate about a beneficial effect of alcohol consumption on IHD [12-14]. High prevalence of both exposure and disease make this question a frequent topic among general practitioners, researchers, media, and the public. Aside from numerous individual studies, several meta-analyses published in the last decade have summarized the association between alcohol consumption and IHD risk.

Most meta-analyses of epidemiological data have shown a mix between a beneficial and detrimental association from alcohol consumption on IHD that depends on the level of average consumption. This relationship is most often described as curvilinear, or 'I-shaped' $[15,16]$, but also sometimes as a flattened-out inverse association $[15,17,18]$. The specific shape of the risk curve seems to depend at least on sex and IHD outcome (mortality versus morbidity). Findings of a beneficial effect are supported by a substantial number of short-term experimental studies on the effect of alcohol consumption on several surrogate biomarkers for IHD in a dose-dependent relationship $[19,20]$, including improved lipid profiles, inhibition of platelet activation, reduction of fibrinogen levels, and antiinflammatory effects. In particular, high density lipoprotein (HDL) cholesterol levels have a clear dose-response relationship with alcohol consumption, with the highest levels observed in people with the highest alcohol consumption [21,22]. Many criticisms have arisen over the last three decades questioning the relationship found in epidemiological studies because of limited quality of alcohol assessment, the influence of drinking pattern, adjustment for confounding, or the inability for observational studies to determine causality $[13,23]$. Although criteria for a causal relationship [24] seem to be fulfilled (see also $[15,18])$, a direct link for alcohol consumption on IHD risk from long-term randomized trials is currently, and for the foreseeable future, missing. Thus, epidemiological studies, as is the case for many other IHD risk factors, play an important role in assessing the role of alcohol consumption on disease risk. The objective of this review is to examine the evidence available to define the relationship between alcohol consumption and IHD based mainly on systematic reviews and meta-analyses, with a focus on the reference group (that is, the use of lifetime abstainers and not current abstainers as the reference group because of the 'sick-quitter' effect [25]); the influence of drinking pattern (in particular episodic heavy drinking among on average moderate drinkers [26]); and the influence of several other important risk factors for IHD, such as age, smoking status, physical activity, and body mass index (BMI), all of which might confound risk estimates for alcohol.

\section{Methods \\ Searches}

Using Preferred Reporting Items for Systematic Reviews and Meta-Analyses (PRISMA) guidelines [27], we conducted two systematic searches in electronic databases from 1980 up to second week of August. First, we searched electronic databases for meta-analyses on alcohol consumption and IHD risk. Second, we searched for original articles, excluding letters, editorials, conference abstracts, reviews, and comments, for variations of search terms for the exposure (alcohol consumption), outcome (IHD), and study design based on previous meta-analyses $[15,26]$. For details, please see Additional file 1: Text S1, Figures S1 and S2. Additionally, we hand-searched references of identified papers and relevant reviews and metaanalyses. Using articles reviewed in these two searches, we examined the role of the reference group, average alcohol consumption, drinking patterns, confounders, and experimental evidence on the alcohol-IHD relationship in a narrative review, and conducted a quantitative analysis on drinking patterns among on average moderate alcohol drinkers in relation to lifetime abstention.

\section{Meta-analysis}

\section{Inclusion and exclusion criteria}

Inclusion criteria for a quantitative analysis of drinking patterns in relation to lifetime abstainers were as follows: adult ( $\geq 18$ years) population samples; IHD analyzed as a separate outcome (International Classification of Diseases (ICD)-9: 410-414, ICD-10: I20-25); case-control, prospective, or historical cohort study design; alcohol exposure measurement covering a reference period of more than 2 weeks for average alcohol consumption at baseline; a drinking group that either specifically excluded or included episodic heavy drinking among current drinkers with an average alcohol consumption $<30 \mathrm{~g}$ of pure alcohol per day; a measure of risk in comparison to lifetime abstainers and its corresponding measure of variability was reported (or sufficient data to calculate these); and English, German, or Spanish language. We excluded selfreported IHD outcomes and samples from people with IHD-related conditions.

\section{Data abstraction}

For the meta-analyses on drinking patterns in reference to lifetime abstention, we extracted from all relevant articles authors' names, year of publication, country, calendar year(s) of baseline examination, follow-up period, setting, 
assessment of IHD and alcohol consumption, mean and range of age at baseline, sex, number of observed IHD cases or deaths among participants by drinking group, number of total participants by drinking group, adjustment for potential confounders, and relative risk (RR) and its standard error. We used the most adjusted RR reported, and gave priority to estimates comparing drinking to lifetime abstainers. Information found in related papers from the same cohort was used where possible. The first author performed the literature search and abstracted the data. Full-text articles with potential eligibility were discussed by both authors until consensus was reached. Primary authors were not contacted where there was not enough information presented in the article.

\section{Statistical analysis}

Hazard ratios, odds ratios, and RRs were treated as equivalent measures of risk. If necessary, RRs within studies were re-calculated based on the method described by Hamling et al. [28] and pooled across studies using inverse-variance weighted DerSimonian-Laird randomeffect models to allow for between-study heterogeneity [29]. We quantified between-study heterogeneity using Cochran's Q [30] and the $\mathrm{I}^{2}$ statistic [31]. $\mathrm{I}^{2}$ can be interpreted as the proportion of the total variation other than chance that is due to heterogeneity between studies. We tested for potential publication bias using Egger's test [32]. Sensitivity analyses for the influence of single studies on the pooled RRs were conducted omitting one study at a time and re-estimating the pooled RR. All meta-analytical procedures were conducted on the natural log scale in Stata statistical software, version 12.1 (Stata Corp, College Station, TX, USA), and $P<0.05$ (two-sided) was considered statistically significant.

\section{Results and discussion}

In the following paragraphs, we describe the results of previous systematic reviews and meta-analyses, and individual studies on alcohol consumption and IHD risk in a narrative review. Furthermore, we meta-analyze the role of heavy drinking patterns in reference to lifetime abstainers using high-quality observational studies.

\section{Lifetime abstainers and former drinkers}

The majority of studies on alcohol consumption and IHD used current abstainers (that is, no current alcohol intake and no assessment of past alcohol intake) as the reference group and thus did not distinguish between lifetime abstainers and former drinkers. For almost 30 years this has been the most important question about the validity of epidemiological findings on the alcohol-IHD relationship. Shaper and colleagues put forward the concept of a 'sickquitter' to describe the elevated risk of many current abstainers and former drinkers for health outcomes [25].
A recent systematic investigation using evidence from 54 epidemiological studies showed that former drinkers were at higher risk for IHD mortality [33]. The pooled IHD mortality risk among former drinkers was 1.54 ( $95 \%$ confidence interval (CI) 1.17 to 2.03 ) in women, and 1.25 (1.15 to 1.36) in men in comparison to lifetime abstainers. The definition of lifetime abstainers (for example, whether less than 12 drinks over the lifetime or very infrequent drinking over the lifetime with no more than 12 drinks in a single year) did not influence the conclusions about this effect. However, it should be noted that a distinction between former drinkers and lifetime abstainers might not be enough to accurately describe IHD risk among current non-drinkers. Rogers et al. [34] found that non-drinkers have different reasons for not drinking and that there is evidence for heterogeneity among non-drinkers that might not be captured completely by dividing non-drinkers into lifetime abstainers and former drinkers.

\section{Average alcohol consumption}

Another recent meta-analysis [15] presented the risk of current drinkers by level of average alcohol intake in comparison to lifetime abstainers where those estimates were available and simultaneously adjusting studies using current abstainers (that is, compensating for the elevated risk in former drinkers) based on the abovementioned meta-analysis. The results clearly showed evidence for a beneficial effect when all available studies were included regardless of sex and IHD outcome (incidence, mortality, or morbidity). In particular, all pooled IHD risk estimates were statistically significant for average alcohol consumption of one to two drinks per day (point estimates were between 0.69 and 0.81 in comparison to lifetime abstainers). The results also showed that the particular J-shape of the association differed by sex and IHD outcome in stratified analyses. Sex seems to be important in that women experience slightly stronger beneficial associations and also a quicker upturn to a detrimental effect at lower levels of average alcohol consumption compared to men [15], which might be related to sex-specific biological factors, such as of body fat distribution, body size, and alcohol solubility [35-37].

Although some meta-analyses $[16,18,38]$ have reported a protective association even for chronic heavy alcohol consumers in population studies (total alcohol intake on average $\geq 60$ g pure alcohol/day), these results need to be interpreted with caution because the reference group is of crucial importance, as shown above. The association seems beneficial among chronic heavy drinkers only when the reference group comprises current abstainers (that is, lifetime abstainers and former drinkers). For example, Ronksley et al. [18] reported a pooled RR of 0.76 (95\% CI 0.52 to 1.09) for IHD incidence and 0.75 (95\% CI 0.63 to 0.89 ) for IHD mortality among chronic 
drinkers consuming $\geq 60 \mathrm{~g} /$ day in comparison to current non-drinkers.

Most recently, a systematic review and meta-analysis [39] demonstrated that chronic heavy drinking does not show any beneficial association with IHD risk when lifetime abstainers are the reference group. IHD mortality risk among male chronic heavy drinkers ( $\geq 60 \mathrm{~g} /$ day) was similar to lifetime abstainers with no indication for a protective association ( $\mathrm{RR}=1.00,95 \%$ CI 0.74 to 1.36 ). Similarly, IHD incidence (that is, using both mortality and morbidity outcomes) showed no indication of a protective effect ( $R R=1.04,95 \%$ CI 0.83 to 1.31) [39]. Such chronic heavy drinking is rarely observed in women in population studies and there are not enough studies to systematically investigate chronic heavy drinking compared to lifetime abstention in women. The above-mentioned IHD mortality risks of average alcohol consumption among men in comparison to lifetime abstainers using data from several previous meta-analyses are displayed in Figure 1.

Whereas the aforementioned investigations were conducted using data from population studies, evidence from clinical samples involving patients with alcohol use disorder (AUD) in alcohol treatment showed a detrimental association with IHD mortality in both men and women $(\mathrm{RR}=1.62,95 \% \mathrm{CI} 1.34$ to 1.95 in men and $\mathrm{RR}=2.09,95 \%$ CI 1.28 to 3.41 in women compared to the general population, see also [42]) in a recent meta-analysis [39]. Patients with AUD are typically missed or underrepresented in population studies [43].

Among those reporting the strongest elevated risk for IHD are studies from Russia [40,41]. These studies consistently report substantially elevated RRs in heavy drinkers; however, alcohol consumption seems so prevalent in Russia that there have not been enough lifetime abstainers to define the risk relationship in comparison to zero alcohol intake over the life course. Nevertheless, the risk among heavy alcohol drinkers in comparison to lowlevel drinkers [40,41] was substantial (Figure 1).

Although no reliable comparisons exist because lifetime abstention is rare in Russia, one can speculate whether the estimates for heavy drinking are over- or underestimates compared to lifetime abstainers. Assuming the reference group ( 0.2 half-liter bottles of vodka per week or $4.6 \mathrm{~g} /$ day on average) has a similar risk compared to low-level drinkers elsewhere $(R R=0.81)$, the adjusted risk would be 1.58 (95\% CI 1.48 to 1.69), only slightly less than assuming the risk among on average low-level drinkers in Russia is indeed equal to that of lifetime abstainers elsewhere $(R R=1.00$, Figure 1$)$. However, given the heavy episodic drinking pattern common in Russia, one would not necessarily expect to find any beneficial effect from any alcohol consumption on IHD risk on a population level as we argue below. Similarly, if one assumes a beneficial effect from average moderate alcohol consumption for $25 \%$ of the population, the risk in male patients with AUD would be slightly less $(\mathrm{RR}=1.36,95 \% \mathrm{CI} 1.13$ to 1.64$)$. In summary, the relationship between average alcohol consumption and IHD risk is clearly J-shaped with an increased IHD risk at high levels of alcohol consumption when compared to lifetime abstainers or low-level drinkers.

\section{Drinking pattern}

Alcohol can be consumed in many different ways, leading to the concern that an episodic heavy drinking pattern may confound or modify the relationship seen for average volume of alcohol intake and IHD risk [44,45].

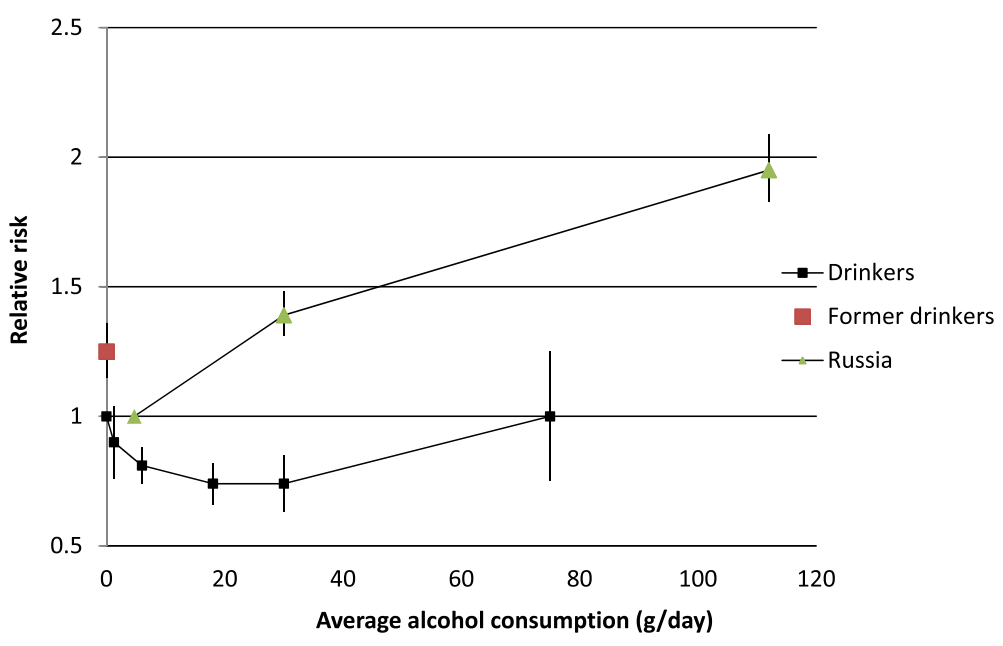

Figure 1 The association of ischemic heart disease mortality with average alcohol consumption in comparison to lifetime abstention in men. Data points taken from published meta-analyses [15,33,39]. All point estimates and confidence intervals were obtained from categorical meta-analyses stratified by alcohol exposure. The Russian estimates were pooled from Zaridze et al. [40,41]. 
McElduff and Dobson were the first to present a stratified risk matrix by amount of alcohol consumption on drinking days and frequency of such drinking days, in the Australian part of the MONICA project looking at myocardial infarction risk [46]. Since then, several other studies have examined the alcohol-IHD relationship with similar detail, making it possible to investigate the influence of drinking patterns more systematically. Excluding the potential problem of lifetime abstainers and former drinkers, a recent meta-analysis examined drinking patterns among current drinkers who were not chronic heavy drinkers (that is, excluding those with average total alcohol intake of $\geq 60 \mathrm{~g} /$ day) [26]. This meta-analysis found a significant difference when comparing episodic heavy drinkers with moderate regular drinkers, with a pooled $\mathrm{RR}=1.45(95 \%$ CI 1.24 to 1.70$)$. Other studies published since then have shown similar findings $[33,47]$.

\section{Meta-analysis on drinking pattern among moderate alcohol drinkers}

In a quantitative meta-analysis paying special attention to the effects of alcohol consumption patterns, we systematically examined IHD risk among two distinct drinking groups with the same average alcohol intake (Figure 2). We identified seven studies providing data on episodic heavy drinking at low to moderate average alcohol consumption ( $<30 \mathrm{~g} /$ day) in comparison to lifetime abstainers (Additional file 1: Table S1, Figures S3 and S4). Compared with lifetime abstainers (that is, not including former drinkers), the pooled RR for IHD incidence was 0.64 (95\% CI 0.53 to 0.71 ) for moderate drinkers without heavy drinking occasions, and 1.12 (95\% CI 0.91 to 1.37) for drinkers with the same average amount who engaged in heavy episodic drinking (Figure 2, Additional file 1: Table S1, Figures S3 and S4). There was no evidence for publication bias $(P=0.35$ and 0.58 for moderate non-heavy drinkers and episodic heavy drinkers, respectively). None of the primary studies in the two meta-analyses had a large influence on the pooled RR estimates. Furthermore, there was very little heterogeneity ( $10 \%$ and $0 \%$, respectively). All studies were adjusted for age and smoking status, five for education and other indicators for socio-economic status, and four each for BMI and marital status.

The corresponding RR between these two drinking groups was 1.75 (95\% CI 1.36 to 2.25 ), higher than the estimate from the previous meta-analysis [26]. In other words, the impact of episodic heavy drinking seems to be greatest at low levels of average alcohol consumption in studies that have separated lifetime abstainers from former drinkers and were well-adjusted for the most relevant potential confounders (Additional file 1: Table S1). Furthermore, the risk estimate for non-heavy low-level drinking was lower (that is, stronger in magnitude for a beneficial effect) than previous investigations of average alcohol consumption without taking into account episodic heavy drinking occasions $[15,18]$.

\section{Studies from Russia}

The importance of drinking patterns becomes particularly important when looking at Russian studies [40,48-50]. A relatively frequent consumption pattern in Russia is episodic heavy to very heavy consumption with sometimes prolonged binges ('zapoi', an episode of continuous drunkenness lasting two or more days in combination with withdrawal from normal social life [51]). This drinking pattern is so extreme that it is heavy with regard to both average and episodic consumption. For example Malyutina et al. [48] in the Russian component of the MONICA project reported that only $7 \%$ of their sample drank $40 \mathrm{~g}$ pure alcohol or less per typical occasion. Moreover, $12 \%$ of this Russian sample were current abstainers, $55 \%$ reported drinking $80 \mathrm{~g}$ or more per typical occasion, and only $8 \%$ had a drinking frequency of more than two days per week. In comparison, the National Health

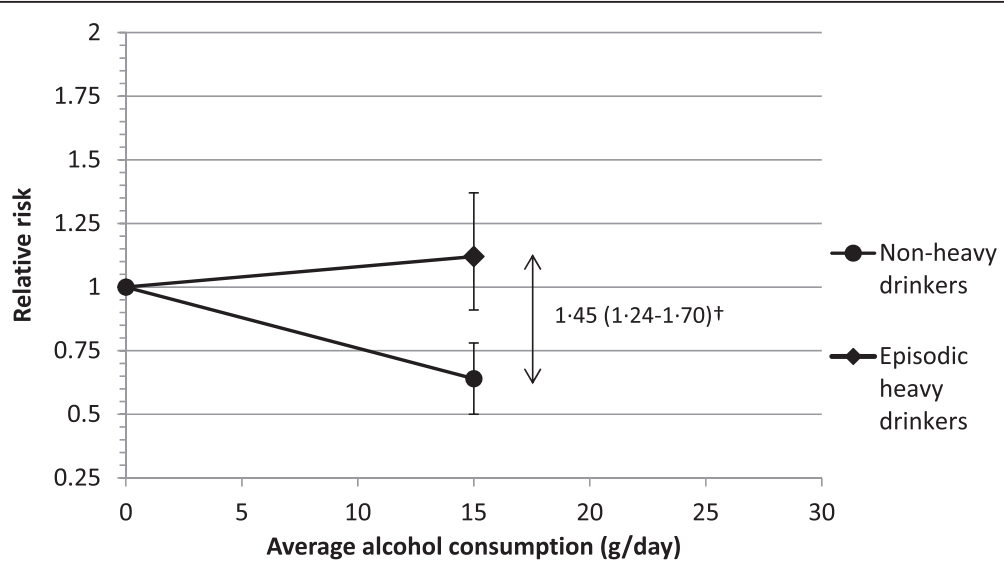

Figure 2 Ischemic heart disease incidence by drinking pattern among drinkers with average consumption of $<30 \mathrm{~g} /$ day in comparison to lifetime abstention. Please see Additional file 1: Table S1, Figures S3 and S4 for details. ${ }^{\dagger}$ Taken from Roerecke \& Rehm [26]. 
Interview Survey cohort from the US had $16 \%$ lifetime abstainers, $15 \%$ former drinkers, $42 \%$ infrequent or moderate drinkers, and only $27 \%$ of the participants drank three or more drinks ( $\geq 36$ g pure alcohol) per drinking day [52].

There is substantial epidemiological evidence showing no protective effect on IHD risk from episodic heavy drinking, whereas the evidence for a beneficial effect of alcohol is substantial and strongest among non-heavy low-level drinkers. In summary, drinking patterns have modifying effects on the relationship between average alcohol consumption and IHD risk.

\section{Confounding from other risk factors for ischemic heart disease}

Residual confounding is an issue for all risk factors for IHD in observational studies. Many risk factors for IHD have been identified [1]. Inclusion of potential confounders had little influence on the pooled risk estimates from meta-analyses examining drinking versus non-drinking status [18]; this finding was similar within categories of average alcohol consumption in a pooled individual-data analysis of eight cohort studies (confounders included age; year of baseline; smoking; BMI; education; physical activity; energy intake; intake of polyunsaturated fat, monounsaturated fat, saturated fat, fiber, and cholesterol; and study design) [53]. Aside from adjustment for confounding, many studies have reported stratified analyses by important risk factors for IHD, which we detail below.

\section{Age}

Hvidtfeldt et al., in a pooled individual-level analysis, showed an inverse relationship for each sex and each of three age groups based on eight cohort studies with 250,000 participants [53]. An inverse relationship based on 64,000 participants stratified into below 60 years of age and 60 years or above has been shown in Chinese men [54]. An analysis of the male British Doctors cohort found an inverse relationship both among participants younger than 75 years and those 75 years and above [55]. In a case-control study from Japan, Miyake found an inverse relationship both among participants younger than 65 years and those 65 years and above [56]. A casecontrol study from Portugal showed a U-shape in those under 45 years of age and an elevated risk only in study participants drinking more than $60 \mathrm{~g}$ of alcohol per day among participants 45 years or older [57]. The Honolulu Heart Program cohort showed an inverse relationship both among participants aged between 51 and 65 years and those 65 to 75 years old [58].

\section{Smoking}

Although numerous modifiable risk factors for IHD have been identified, their influence on the alcohol-IHD relationship seems to be small, except for smoking. Smoking is, aside from age, the most important risk factor for IHD, and several studies have provided evidence on its influence on the alcohol-IHD relationship. It should be noted that alcohol is one of the most investigated risk factors for IHD [59]. Inoue et al., in a pooled individual analysis by smoking status, showed a J-shape in never smokers and a U-shape in current smokers, with the highest category of average alcohol consumption being $92 \mathrm{~g} /$ day or more in 300,000 Japanese participants [60]. A Chinese cohort study showed a similar inverse relationship in both current smokers and current nonsmokers [54]. An inverse relationship among never smokers, a U-shape in former smokers, and an exponential relationship in current smokers was reported in a male Scottish sample of factory workers between 35 and 64 years old and with 30 years of follow-up [61]. Ebbert et al. showed an inverse relationship among never smokers and former smokers, and no relationship among current smokers in a low consumption cohort the Iowa Women's Health study [62]. An analysis of the Framingham study with 24 years of follow-up showed an inverse relationship among non-smokers, no relationship among light smokers ( $\leq 1$ pack/day), and an inverse relationship among heavy smokers ( $>1$ pack/day) in men. In women, a U-shape was found among nonsmokers and smokers [63]. An analysis of the British Regional Heart Study showed an inverse relationship among former smokers, no relationship among current smokers, and an unclear relationship among never smokers. However, there were too few IHD deaths among never drinkers to reach a firm conclusion [64]. In an investigation of the National Health and Nutrition Examination Survey (NHANES I) in women 45 to 74 years old, an inverse relationship in both smokers and non-smokers was reported [65].

In sum, regarding average alcohol consumption, in all but one population study an inverse or J-shaped curve was observed in never or non-smokers. Evidence in smokers is mixed. Some studies reported an inverse relationship, some a threshold relationship, and some no clear relationship. Regarding clinical samples of patients in AUD treatment, there is the possibility that the detrimental association from alcohol consumption is overestimated because of uncontrolled confounding from smoking in these samples. However, the prospective Russian study by Zaridze et al. [41] clearly showed a substantially increasing risk with increasing alcohol consumption among male smokers.

\section{Other confounding factors}

Some evidence stratified by physical activity and BMI for the alcohol-IHD relationship exists. Pedersen et al. investigated fatal IHD in the Copenhagen City Heart Study [66]. They found an inverse relationship for both 
physical activity level and average alcohol consumption in a low consumption cohort. The risk for non-drinkers and drinkers having less than one drink per week was consistently higher compared to drinkers having one to 14 drinks per week and 15 or more drinks. They concluded that both physical activity and alcohol consumption were factors for lower IHD risk. Bazzano et al. found an inverse relationship for participants with a $\mathrm{BMI} \geq 25$ and $<25$, with stronger evidence among those with a BMI $<25$ [54].

In sum, the epidemiological evidence shows that only in smokers there is some evidence that there is no beneficial association of alcohol consumption, and possibly a threshold effect, pointing to possible effect modification with alcohol consumption. Evidence for a beneficial association was consistent across age groups and in nonsmokers. Available evidence for the influence of physical activity and BMI is sparse, although this evidence points to a beneficial association, as well. Furthermore, a beneficial association has been observed in patients who are hypertensive, diabetic, have cardiovascular diseases, and who are survivors of myocardial infarction [67-73]. An inverse relationship has been observed in healthy individuals in a US cohort [74], and no association in a UK cohort [75].

\section{Experimental evidence}

Long-term randomized studies on alcohol exposure and IHD mortality or morbidity in the general population are unavailable. Regular alcohol intake has been found to have beneficial, dose-dependent effects on surrogate biomarkers for IHD risk in short-term experimental studies, mainly by increasing HDL cholesterol levels, inhibiting platelet activation, reducing fibrinogen levels, and producing anti-inflammatory effects $[19,76]$. The increase in HDL cholesterol was also evident in experimental studies with regular heavy drinking ( $\geq 60 \mathrm{~g} /$ day every day) [77-82], and the highest levels of HDL cholesterol are found in people with AUD [21]. Despite elevated levels of HDL cholesterol even in regular heavy alcohol consumers [83], an increase in low-density lipoprotein (LDL) and other detrimental effects of episodic and chronic heavy alcohol consumption on heart disease risk seem to negate those beneficial effects, resulting in an overall neutral or detrimental association. The detrimental effect on blood pressure and arrhythmias [44,84-90] and atrial fibrillation [44,89,91-93], in particular from episodic and chronic heavy drinking, might play a role here, in combination with anti-atherosclerotic and anti-thrombotic processes. Although systematic experimental evidence for the effect of episodic heavy drinking is limited, the biochemical effects might involve HDL and LDL cholesterol levels, arrhythmias, and thrombosis [45]. It seems that episodic heavy drinking increases LDL cholesterol levels without a favorable effect on HDL [45], and possibly a transient detrimental effect on thrombosis, hypertension, and arrhythmias [44,45]. Prolonged chronic heavy drinking can result in the most extreme form of cardiac tissue damage, cardiomyopathy [94].

Recently, using Mendelian randomization, Holmes et al. [95] examined the impact of alcohol dehydrogenase $1 \mathrm{~B}$ alleles on IHD risk, and concluded that for every level of alcohol consumption, an increase in average consumption was associated with an increase in IHD risk, that is, no protective effect. The rs1229984 A-allele is associated with lower alcohol consumption due to negatively experienced effects (including a flushing response) caused by the fast metabolization of alcohol into acetaldehyde [96]. This study design can be seen as quasi-randomized, assuming the rs1229984 A-allele is randomly distributed in the population, thus noncarriers having the same IHD risk aside from the effect of the rs1229984 A-allele. An additional assumption has to be for conclusions regarding the absence of a protective effect that the effect of the polymorphism is entirely mediated via average alcohol consumption. However, Holmes et al. showed that, aside from the association with lower average alcohol consumption, the rs1229984 A-allele was also related to less binge drinking. As we have shown above, both average alcohol consumption and drinking patterns interact in a complex way with regard to IHD risk, and the alcohol-heart relationship cannot be accurately described using only one of the dimensions of alcohol intake. Taken together, it is difficult to compare the results from Holmes et al. to the epidemiological literature we have described here. Nevertheless, Mendelian randomization studies may become a very useful tool in widening the evidence base for a causal relation between alcohol consumption and IHD risk, together with both observational and experimental studies on the specific effects of drinking patterns on the heart (please see also [97]).

Thus, there is substantial experimental evidence for a beneficial effect of low to moderate regular alcohol consumption on IHD, which disappears for episodic heavy drinking. Novel study designs may help in improving knowledge of the complex relationship between alcohol and IHD risk.

\section{Conclusions}

Alcohol's effect on the human body and mind is quite strong, even at low doses [98]. Its neuro-toxic, hepatotoxic, and carcinogenic properties make it a potent risk factor for disease burden. However, its effect on IHD risk also makes it an intriguing and sometimes controversial topic in disease epidemiology and public policy. The quality of epidemiological studies has substantially improved over the last three decades. Using current abstainers 
as the reference group leads to systematic bias and erroneous conclusions. Using high-quality epidemiological evidence, a clear picture supported by short-term experimental evidence emerges. When examining average alcohol consumption in comparison to lifetime abstainers, the relationship with IHD risk follows a J-curve. The curve turns into a detrimental association for much lower average alcohol levels in women compared with men.

However, average alcohol consumption alone is not sufficient to describe the alcohol-IHD relationship. Drinking patterns play an important role and both episodic and chronic heavy drinking negate any beneficial association with IHD risk, or elevate the risk substantially. Nevertheless, for drinkers having one to two drinks per drinking day without episodic heavy drinking, there is substantial and consistent evidence from epidemiological and shortterm experimental studies for a beneficial association with IHD risk when compared to lifetime abstainers. The alcohol-IHD relationship fulfills all criteria for a causal association proposed by Hill [24]. Whether one is able to detect an inverse, U-shaped, or J-shaped relationship depends on the distribution of drinking pattern in a given population. Prevalence of heavy drinking patterns has been on the rise in many countries, such as Canada, the US, the UK, and many Eastern European and Asian countries [99-102]. In the US, episodic heavy drinking is more common than chronic heavy drinking [102].

Aside from any effect on IHD, caution must be used when judging the overall risk-benefit relationship of any form of alcohol consumption on an individual level because of well-known detrimental effects on other disease outcomes, such as injuries and cancer $[6,7,103]$. Recommendations for clinical practitioners (aside from clear contra-indications because of other illnesses or medication intake) remain challenging because of the apparent simultaneous beneficial and detrimental effects from on average low alcohol consumption, and the fact that evidence from randomized controlled trials on long-term effects of alcohol consumption is and will be unavailable. Furthermore, there is no control mechanism for alcohol purchase as there is for prescription drugs because alcohol is freely available for self- and over-medication. Therefore, uptake of alcohol consumption should not be considered as a treatment option in prevention of IHD. In terms of public alcohol policy, the picture is clear: alcohol consumption should be as low as possible, no amount of consumption is safe, and any type of episodic and chronic heavy drinking should be strongly discouraged $[104,105]$.

\section{Additional file}

Additional file 1: Text S1. Systematic review protocols for narrative and quantitative reviews. Figure $\mathbf{S} 1$. Search results for meta-analyses on alcohol consumption and IHD risk. Figure S2. Search results for population studies on non-heavy and heavy alcohol consumption and IHD risk. Table S1. Characteristics of seven studies on IHD risk in people with 1 to $30 \mathrm{~g}$ /day average alcohol consumption in comparison to lifetime abstainers. Figure S3. IHD risk among non-heavy drinkers with total average intake of 1 to $30 \mathrm{~g}$ /day compared with lifetime abstainers. Figure S4. IHD risk among episodic heavy drinkers with total average intake of 1 to $30 \mathrm{~g} /$ day compared with lifetime abstainers.

\section{Abbreviations}

AUD: alcohol use disorder; BMl: body mass index; $\mathrm{Cl}$ : confidence interval; HDL: high-density lipoprotein; ICD: International Classification of Diseases; IHD: ischemic heart disease; LDL: low-density lipoprotein; RR: relative risk.

\section{Competing interests}

The authors declare that they have no competing interests.

\section{Authors' contributions}

MR led protocol design, study design, the literature review, data extraction, statistical analysis, data interpretation, article preparation, article review, and correspondence. JR contributed to protocol design, study design, the literature review, data extraction, statistical analysis, data interpretation, article preparation, article review, and correspondence. Both authors have read and approved the final manuscript.

\section{Acknowledgments}

The research leading to these results or outcomes received funding from the European Community's Seventh Framework Programme (FP7/2007-2013) under Grant Agreement no. 266813 - Addictions and Lifestyle in Contemporary Europe - Reframing Addictions Project (ALICE RAP http://www.alicerap.eu). Participant organizations in ALICE RAP can be seen at http://www.alicerap. eu/about-alice-rap/partner-institutions.html. The views expressed here reflect only the authors' and the European Union is not liable for any use that may be made of the information contained therein.

\section{Author details}

${ }^{1}$ Social and Epidemiological Research Department, Centre for Addiction and Mental Health (CAMH), 33 Russell Street, Toronto, Ontario M5S 2S1, Canada. ${ }^{2}$ Dalla Lana School of Public Health (DLSPH), University of Toronto, Toronto, Canada. ${ }^{3}$ Institute of Medical Science, University of Toronto, Toronto, Canada. ${ }^{4}$ Institute for Clinical Psychology and Psychotherapy, TU Dresden, Dresden, Germany. ${ }^{5}$ Department of Psychiatry, University of Toronto, Toronto, Canada.

Received: 17 June 2014 Accepted: 10 September 2014

Published online: 21 October 2014

\section{References}

1. Go AS, Mozaffarian D, Roger VL, Benjamin EJ, Berry JD, Blaha MJ, Dai S, Ford ES, Fox CS, Franco S, Fullerton HJ, Gillespie C, Hailpern SM, Heit JA, Howard VJ, Huffman MD, Judd SE, Kissela BM, Kittner SJ, Lackland DT, Lichtman JH, Lisabeth LD, Mackey RH, Magid DJ, Marcus GM, Marelli A, Matchar DB, McGuire DK, Mohler ER 3rd, Moy CS, et al: Heart disease and stroke statistics-2014 update: a report from the American Heart Association. Circulation 2014, 129:e28-e292.

2. Nichols M, Townsend N, Scarborough P, Rayner M: Cardiovascular disease in Europe: epidemiological update. Eur Heart J 2013, 34:3028-3034.

3. Lozano R, Naghavi M, Foreman K, Lim S, Shibuya K, Aboyans V, Abraham J, Adair T, Aggarwal R, Ahn SY, Alvarado M, Anderson HR, Anderson LM, Andrews KG, Atkinson C, Baddour LM, Barker-Collo S, Bartels DH, Bell ML, Benjamin EJ, Bennett D, Bhalla K, Bikbov B, Bin Abdulhak A, Birbeck G, Blyth F, Bolliger I, Boufous S, Bucello C, Burch M, et al: Global and regional mortality from 235 causes of death for 20 age groups in 1990 and 2010: a systematic analysis for the Global Burden of Disease Study 2010. Lancet 2012, 380:2095-2128.

4. Murray CJ, Vos T, Lozano R, Naghavi M, Flaxman AD, Michaud C, Ezzati M, Shibuya K, Salomon JA, Abdalla S, Aboyans V, Abraham J, Ackerman I, Aggarwal R, Ahn SY, Ali MK, Alvarado M, Anderson HR, Anderson LM, Andrews KG, Atkinson C, Baddour LM, Bahalim AN, Barker-Collo S, Barrero LH, Bartels DH, Basáñez MG, Baxter A, Bell ML, Benjamin EJ, et al: Disability-adjusted life years (DALYs) for 291 diseases and injuries in 
21 regions, 1990-2010: a systematic analysis for the Global Burden of Disease Study 2010. Lancet 2012, 380:2197-2223.

5. Lim SS, Vos T, Flaxman AD, Danaei G, Shibuya K, Adair-Rohani H, Amann M, Anderson HR, Andrews KG, Aryee M, Atkinson C, Bacchus LJ, Bahalim AN, Balakrishnan K, Balmes J, Barker-Collo S, Baxter A, Bell ML, Blore JD, Blyth F, Bonner C, Borges G, Bourne R, Boussinesq M, Brauer M, Brooks P, Bruce NG, Brunekreef B, Bryan-Hancock $C$, Bucello $C$, et al: A comparative risk assessment of burden of disease and injury attributable to 67 risk factors and risk factor clusters in 21 regions, 1990-2010: a systematic analysis for the Global Burden of Disease Study 2010. Lancet 2012, 380:2224-2260.

6. Rehm J, Mathers C, Popova S, Thavorncharoensap M, Teerawattananon Y, Patra J: Global burden of disease and injury and economic cost attributable to alcohol use and alcohol use disorders. Lancet 2009, 373:2223-2233.

7. International Agency for Research on Cancer: IARC Monographs on the Evaluation of Carcinogenic Risks to Humans: Alcohol Consumption and Ethyl Carbamate. Lyon, France: International Agency for Research on Cancer; 2010.

8. International Agency for Research on Cancer: Personal Habits and Indoor Combustions. Lyon, France: International Agency for Research on Cancer; 2012.

9. Rehm J, Shield K: Alcohol consumption. In World Cancer Report. Edited by Steward BW, Wild CP. Lyon: International Agency for Research on Cancer; 2014:97-1070

10. Rehm J, Shield KD: Alcohol and mortality. Global alcohol-attributable deaths from cancer, liver cirrhosis, and injury in 2010. Alcohol Res 2013, 35:174-183.

11. Rehm J, Samokhvalov AV, Shield KD: Global burden of alcoholic liver diseases. J Hepatol 2013, 59:160-168.

12. Fekjaer HO: Alcohol-a universal preventive agent? A critical analysis. Addiction 2013, 108:2051-2057.

13. Jackson R, Broad J, Connor J, Wells S: Alcohol and ischaemic heart disease: probably no free lunch. Lancet 2005, 366:1911-1912.

14. Goldberg IJ: To drink or not to drink? N Engl J Med 2003, 348:163-164.

15. Roerecke M, Rehm J: The cardioprotective association of average alcohol consumption and ischaemic heart disease: a systematic review and meta-analysis. Addiction 2012, 107:1246-1260.

16. Corrao G, Rubbiati L, Bagnardi V, Zambon A, Poikolainen K: Alcohol and coronary heart disease: a meta-analysis. Addiction 2000, 95:1505-1523.

17. Maclure M: Demonstration of deductive meta-analysis: ethanol intake and risk of myocardial infarction. Epidemiol Rev 1993, 15:328-351.

18. Ronksley PE, Brien SE, Turner BJ, Mukamal KJ, Ghali WA: Association of alcohol consumption with selected cardiovascular disease outcomes: a systematic review and meta-analysis. BMJ 2011, 342:d671.

19. Brien SE, Ronksley PE, Turner BJ, Mukamal KJ, Ghali WA: Effect of alcoho consumption on biological markers associated with risk of coronary heart disease: systematic review and meta-analysis of interventional studies. BMJ 2011, 342:d636.

20. Rimm EB, Williams P, Fosher K, Criqui MH, Stampfer MJ: Moderate alcoho intake and lower risk of coronary heart disease: meta-analysis of effects on lipids and haemostatic factors. BMJ 1999, 19:1523-1528.

21. Seppä K, Sillanaukee P, Pitkäjärvi T, Nikkilä M, Koivula T: Moderate and heavy alcohol consumption have no favorable effect on lipid values. Arch Intern Med 1992, 152:297-300.

22. Wakabayashi I: Associations between alcohol drinking and multiple risk factors for atherosclerosis in smokers and nonsmokers. Angiology 2010, 61:495-503.

23. Chikritzhs T, Fillmore K, Stockwell T: A healthy dose of scepticism: four good reasons to think again about protective effects of alcohol on coronary heart disease. Drug Alcohol Rev 2009, 28:441-444.

24. Hill A: The environment and disease: association or causation? Proc $R$ Soc Med $1965,58: 295-300$

25. Shaper A, Wannamethee G, Walker M: Alcohol and mortality in British men: explaining the U-shaped curve. Lancet 1988, 2:1267-1273.

26. Roerecke $M$, Rehm J: Irregular heavy drinking occasions and risk of ischemic heart disease: a systematic review and meta-analysis. Am J Epidemiol 2010, 171:633-644.

27. Moher D, Liberati A, Tetzlaff J, Altman DG, The Prisma Group: Preferred reporting items for systematic reviews and meta-analyses: the PRISMA Statement. PLoS Med 2009, 6:e1000097.

28. Hamling J, Lee $P$, Weitkunat $R$, Ambühl M: Facilitating meta-analyses by deriving relative effect and precision estimates for alternative comparisons from a set of estimates presented by exposure level or disease category. Stat Med 2008, 27:954-970
29. DerSimonian R, Laird N: Meta-analysis in clinical trials. Control Clin Trials 1986, 7:177-188

30. Cochran WG: The combination of estimates from different experiments Biometrics 1954, 10:101-129.

31. Higgins JP, Thompson SG: Quantifying heterogeneity in a meta-analysis. Stat Med 2002, 21:1539-1558.

32. Egger M, Smith GD, Schneider M, Minder C: Bias in meta-analysis detected by a simple, graphical test. BMJ 1997, 315:629-634.

33. Roerecke $M$, Rehm J: Ischemic heart disease mortality and morbidity in former drinkers: a meta-analysis. Am J Epidemiol 2011, 73:245-258.

34. Rogers RG, Krueger PM, Miech R, Lawrence EM, Kemp R: Nondrinker mortality risk in the United States. Popul Res Policy Rev 2013, 32:325-352.

35. Frezza M, di Padova C, Pozzato G, Terpin M, Baraona E, Lieber CS: High blood alcohol levels in women. The role of decreased gastric alcohol dehydrogenase activity and first-pass metabolism. N Engl J Med 1990, 322:95-99.

36. Kwo PY, Pamchandani VA, O'Connor S, Amann D, Carr LG, Sandrasegaran K, Kopecky KK, Li TK: Gender differences in alcohol metabolism: relationship to liver volume and effect of adjusting for body mass. Gastroenterology 2012, 115:1552-1557.

37. Meister KA, Whelan EM, Kava R: The health effects of moderate alcohol intake in humans: an epidemiologic review. Crit Rev Clin Lab Sci 2000, 37:261-296.

38. Bagnardi V, Zatonski W, Scotti L, La Vecchia C, Corrao G: Does drinking pattern modify the effect of alcohol on the risk of coronary heart disease? Evidence from a meta-analysis. J Epidemiol Community Health 2008, 62:615-619.

39. Roerecke M, Rehm J: Chronic heavy drinking and ischaemic heart disease: a systematic review and meta-analysis. Open Heart 2014, 1: doi:10.1136/ openhrt-2014-000135.

40. Zaridze D, Brennan P, Boreham J, Boroda A, Karpov R, Lazarev A, Konobeevskaya I, Igitov V, Terechova T, Boffetta P, Peto R: Alcohol and cause-specific mortality in Russia: a retrospective case-control study of 48,557 adult deaths. Lancet 2009, 373:2201-2214.

41. Zaridze D, Lewington S, Boroda A, Scélo G, Karpov R, Lazarev A, Konobeevskaya I, Igitov V, Terechova T, Boffetta P, Sherliker P, Kong X, Whitlock G, Boreham J, Brennan P, Peto R: Alcohol and mortality in Russia: prospective observational study of 151,000 adults. Lancet 2014, 383:1465-1473.

42. Roerecke M, Rehm J: Cause-specific mortality risk in alcohol use disorder treatment patients: a systematic review and meta-analysis. Int J Epidemiol 2014, 43:906-919.

43. Rehm J, Gmel G, Sempos C, Trevisan M: Alcohol-related mortality and morbidity. Alcohol Res Health 2003, 27:39-51.

44. Puddey IB, Rakic V, Dimmitt SB, Beilin LJ: Influence of pattern of drinking on cardiovascular disease and cardiovascular risk factors - a review. Addiction 1999, 94:649-663.

45. McKee M, Britton $\mathrm{A}$ : The positive relationship between alcohol and heart disease in Eastern Europe: potential physiological mechanisms. $J R$ Soc Med 1998, 91:402-407.

46. McElduff P, Dobson AJ: How much alcohol and how often? Population based case-control study of alcohol consumption and risk of a major coronary event. BMJ 1997, 314:1159-1164.

47. Ruidavets JB, Ducimetière $P$, Evans A, Montaye $M$, Haas B, Bingham A Yarnell J, Amouyel P, Arveiler D, Kee F, Bongard V, Ferrières J: Patterns of alcohol consumption and ischaemic heart disease in culturally divergent countries: the Prospective Epidemiological Study of Myocardial Infarction (PRIME). BMJ 2010, 341:C6077.

48. Malyutina S, Bobak M, Kurilovitch S, Gafarov V, Simonova G, Nikitin Y Marmot M: Relation between heavy and binge drinking and all-cause and cardiovascular mortality in Novosibirski, Russia: a prospective cohort study. Lancet 2002, 360:1448-1454.

49. Leon DA, Shkolnikov VM, McKee M, Kiryanov N, Andreev E: Alcohol increases circulatory disease mortality in Russia: acute and chronic effects or misattribution of cause? Int J Epidemiol 2010, 39:1279-1290.

50. Sidorenkov O, Nilssen O, Grjibovski AM: Determinants of cardiovascular and all-cause mortality in northwest Russia: a 10-year follow-up study. Ann Epidemiol 2012, 22:57-65.

51. Tomkins S, Saburova L, Kiryanov N, Andreev E, McKee M, Shkolnikov V, Leon DA: Prevalence and socio-economic distribution of hazardous patterns of alcohol drinking: study of alcohol consumption in men aged 25-54 years in lzhevsk. Russia Addict 2007, 102:544-553. 
52. Rostron B: Alcohol consumption and mortality risks in the USA. Alcohol Alcohol 2012, 47:334-339.

53. Hvidtfeldt UA, Tolstrup JS, Jakobsen MU, Heitmann BL, Grønbaek M, O'Reilly E, Bälter K, Goldbourt U, Hallmans G, Knekt P, Liu S, Pereira M, Pietinen P, Spiegelman D, Stevens J, Virtamo J, Willett WC, Rimm EB, Ascherio A: Alcohol intake and risk of coronary heart disease in younger, middle-aged, and older adults. Circulation 2010, 121:1589-1597.

54. Bazzano LA, Gu DF, Reynolds K, Chen J, Wu XQ, Chen CS, Duan XF, Chen JC, He J: Alcohol consumption and risk of coronary heart disease among Chinese men. Int J Cardiol 2009, 135:78-85.

55. Doll R, Peto R, Hall E, Wheatley K, Gray R: Mortality in relation to consumption of alcohol: 13 years' observations on male British doctors. BMJ 1994, 309:911-918.

56. Miyake $Y$ : Risk factors for non-fatal acute myocardial infarction in middle-aged and older Japanese. Fukuoka Heart Study Group. Jpn Circ J 2000, 64:103-109.

57. Oliveira A, Barros H, Azevedo A, Bastos J, Lopes C: Impact of risk factors for non-fatal acute myocardial infarction. Eur J Epidemiol 2009, 24:425-432.

58. Goldberg RJ, Burchfield CM, Reed DM, Wergowske G, Chiu D: A prospective study of the health effects of alcohol consumption in middle-aged and elderly men: the Honolulu Heart Program. Circulation 1994, 89:651-659.

59. Mente A, de Koning L, Shannon HS, Anand SS: A systematic review of the evidence supporting a causal link between dietary factors and coronary heart disease. Arch Intern Med 2009, 169:659-669.

60. Inoue M, Nagata C, Tsuji I, Sugawara Y, Wakai K, Tamakoshi A, Matsuo K, Mizoue T, Tanaka K, Sasazuki S, Tsugane S, Research Group for the Development and Evaluation of Cancer Prevention Strategies in Japan: Impact of alcohol intake on total mortality and mortality from major causes in Japan: a pooled analysis of six large-scale cohort studies. J Epidemiol Community Health 2012, 66:448-456.

61. Hart CL, Davey Smith G, Gruer L, Watt GC: The combined effect of smoking tobacco and drinking alcohol on cause-specific mortality: a 30 year cohort study. BMC Public Health 2010, 10:789.

62. Ebbert JO, Janney CA, Sellers TA, Folsom AR, Cerhan JR: The association of alcohol consumption with coronary heart disease mortality and cancer incidence varies by smoking history. J Gen Intern Med 2005, 20:14-20.

63. Friedman LA, Kimball AW: Coronary heart disease mortality and alcohol consumption in Framingham. Am J Epidemiol 1986, 124:481-489.

64. Shaper AG, Phillips AN, Pocock SJ, Walker M: Alcohol and ischemic heart disease in middle-aged British men. BMJ 1987, 294:733-737.

65. Garg R, Wagener DK, Madans JH: Alcohol consumption and risk of ischemic heart disease in women. Arch Intern Med 1993, 153:1211-1216.

66. Pedersen $\lrcorner \varnothing$, Heitmann BL, Schnohr P, Grønbaek M: The combined influence of leisure-time physical activity and weekly alcohol intake on fatal ischaemic heart disease and all-cause mortality. Eur Heart J 2008, 29:204-212.

67. Pai JK, Mukamal KJ, Rimm EB: Long-term alcohol consumption in relation to all-cause and cardiovascular mortality among survivors of myocardial infarction: the Health Professionals Follow-up Study. Eur Heart J 2012, 33:1598-1605.

68. Jackson VA, Sesso HD, Buring JE, Gaziano JM: Alcohol consumption and mortality in men with preexisting cerebrovascular disease. Arch Intern Med 2003, 163:1189-1193.

69. Tanasescu M, Hu FB, Willett WC, Stampfer MJ, Rimm EB: Alcohol consumption and risk of coronary heart disease among men with type 2 diabetes mellitus. J Am Coll Cardio/ 2001, 38:1836-1842.

70. Solomon CG, Hu FB, Stampfer MJ, Colditz GA, Speizer FE, Rimm EB, Willett WC, Manson JE: Moderate alcohol consumption and risk of coronary heart disease among women with type 2 diabetes mellitus. Circulation 2000, 102:494-499.

71. Beulens JW, Rimm EB, Stampfer MJ, Ascherio A, Hendriks HF, Mukamal KJ: Alcohol consumption and risk of coronary heart disease in men with hypertension. Ann Intern Med 2007, 146:10-19.

72. Beulens JW, Algra A, Soedamah-Muthu SS, Visseren FL, Grobbee DE, van der Graaf Y, SMART Study Group: Alcohol consumption and risk of recurrent cardiovascular events and mortality in patients with clinically manifest vascular disease and diabetes mellitus: the Second Manifestations of ARTerial (SMART) disease study. Atherosclerosis 2010, 212:281-286.

73. Britton KA, Gaziano JM, Sesso HD, Djoussé L: Relation of alcohol consumption and coronary heart disease in hypertensive male physicians (from the Physicians' Health Study). Am J Cardio/ 2009, 104:932-935.
74. Mukamal KJ, Chiuve SE, Rimm EB: Alcohol consumption and risk for coronary heart disease in men with healthy lifestyles. Arch Intern Med 2006, 166:2145-2150.

75. Britton A, Marmot MG, Shipley M: Who benefits most from the cardioprotective properties of alcohol consumption-health freaks or couch potatoes? J Epidemio/ Community Health 2008, 62:905-908.

76. Brinton EA: Effects of ethanol intake on lipoproteins. Curr Atheroscler Rep 2012, 14:108-114

77. Contaldo F, D'Arrigo E, Carandente V, COrtese C, Coltori A, Mancini M, Taskinen MR, Nikkilä EA: Short-term effects of moderate alcohol consumption on lipid metabolism and energy balance in normal men. Metabolism 1989, 38:166-171

78. Malmendier CL, Delcroix C: Effect of alcohol intake on high and low density lipoprotein metabolism in healthy volunteers. Clin Chem Acta 1985, 152:281-288

79. Crouse JR, Grundy SM: Effects of alcohol on plasma lipoproteins and cholesterol and triglyceride metabolism in man. J Lipid Res 1984, 25:486-496.

80. Belfrange P, Berg B, Cronholm T, Elmqvist D, Hagerstrand I, Johansson B, Nilsson-Ehle P, Nordén G, Sjövall J, Wiebe T: Prolonged administration of ethanol to young, healthy volunteers: effects on biochemical, morphological and neurophysiological parameters. Acta Med Scand 1973, 552:1-44.

81. Belfrage $P$, Berg $B$, Hagerstrand I, Nilsson-Ehle $P$, Tornqvist $H$, Wiebe T: Alterations of lipid metabolism in healthy volunteers during long-term ethanol intake. Eur J Clin Invest 1977, 7:127-131.

82. Välimäki M, Laitinen K, Ylikahri R, Ehnholm C, Jauhianen M, Bard JM, Fruchart JC, Taskinen MR: The effect of moderate alcohol intake on serum apolipoprotein A-I-containing lipoproteins and lipoprotein (a). Metabolism 1991, 40:1168-1172.

83. Peasey A, Bobak M, Malyutina S: Do lipids contribute to the lack of cardio-protective effect of binge drinking: alcohol consumption and lipids in three eastern European countries. Alcohol Alcohol 2005 40:431-435

84. Hillbom M, Saloheimo P, Juvela S: Alcohol consumption, blood pressure, and the risk of stroke. Curr Hypertens Rep 2011, 13:208-213.

85. Rakic V, Puddey IB, Burke V, Dimmitt SB, Beilin LJ: Influence of pattern of alcohol intake on blood pressure in regular drinkers: a controlled trial. J Hypertens 1998, 16:165-174

86. Marmot MG, Elliott P, Shipley MJ, Dyer AR, Ueshima H, Beevers DG, Stamler R, Kesteloot H, Rose G, Stamler J: Alcohol and blood pressure: the INTERSALT study. BMJ 1994, 308:1263-1267.

87. Pajak A, Szafraniec K, Kubinova R, Malyutina S, Peasey A, Pikhart H, Nikitin Y, Marmot M, Bobak M: Binge drinking and blood pressure: cross-sectional results of the HAPIEE study. PLOS One 2013, 8:e65856.

88. Seppa K, Sillanaukee P: Binge drinking and ambulatory blood pressure. Hypertension 1999, 33:79-82.

89. Zakhari S: Alcohol and the cardiovascular system: molecular mechanisms for beneficial and harmful action. Alcohol Res Health 1997, 21:21-29.

90. Taylor B, Irving HM, Baliunas D, Roerecke M, Patra J, Mohapatra S, Rehm J: Alcohol and hypertension: gender differences in dose-response relationships determined through systematic review and meta-analysis. Addiction 2009, 104:1981-1990.

91. Britton A, McKee M: The relation between alcohol and cardiovascular disease in Eastern Europe: explaining the paradox. J Epidemiol Community Health 2000, 54:328-332.

92. Menezes AR, Lavie CJ, DiNicolantonio JJ, O'Keefe J, Morin DP, Khatib S, Milani RV: Atrial fibrillation in the 21st century: a current understanding of risk factors and primary prevention strategies. Mayo Clin Proc 2013, 88:394-409.

93. Samokhvalov AV, Irving HM, Rehm J: Alcohol as a risk factor for atrial fibrillation: a systematic review and meta-analysis. Eur J Cardiovasc Prev Rehabil 2010, 17:706-712.

94. Di Minno MN, Franchini M, Russolillo A, Lupoli R, lervolino S, Di Minno G: Alcohol dosing and the heart: updating clinical evidence. Semin Thromb Hemost 2011, 37:875-884.

95. Holmes MV, Dale CE, Zuccolo L, Silverwood RJ, Guo Y, Ye Z, Prieto-Merino D, Dehghan A, Trompet S, Wong A, Cavadino A, Drogan D, Padmanabhan S, Li S, Yesupriya A, Leusink M, Sundstrom J, Hubacek JA, Pikhart H, Swerdlow DI, Panayiotou AG, Borinskaya SA, Finan C, Shah S, Kuchenbaecker KB, Shah T, Engmann J, Folkersen L, Eriksson P, Ricceri F, et al: Association between alcohol and cardiovascular disease: Mendelian randomisation analysis based on individual participant data. BMJ 2014, 349:94164. 
96. Zakhari S: Overview: how is alcohol metabolized by the body? Alcohol Res Health 2006, 29:245-254.

97. Rehm J, Roerecke M: Time to rethink the ischaemic heart disease effects of low to moderate alcohol consumption? BMJ 2014, http://www.bmj. com/content/349/bmj.g4164/rapid-responses.

98. Eckardt M, File S, Gessa G, Grant K, Guerri C, Hoffman P, Kalant H, Koop G, Li $T$, Tabakoff B: Effects of moderate alcohol consumption on the central nervous system. Alcohol Clin Exp Res 1998, 22:998-1040.

99. Shield K, Rylett M, Gmel G, Gmel G, Kehoe-Chan T, Rehm J: Global alcohol exposure estimates by country, territory and region for 2005 - a contribution to the Comparative Risk Assessment for the 2010 Global Burden of Disease Study. Addiction 2013, 108:912-922.

100. Center for Disease Control and Prevention: Vital signs: binge drinking prevalence, frequency, and intensity among adults-U.S., 2010. MMWR Morb Mortal Wkly Rep 2012, 61:14-19.

101. Serdula MK, Brewer RD, Gillespie C, Denny CH, Mokdad A: Trends in alcohol use and binge drinking, 1985-1999: results of a multi-state survey. Am J Prev Med 2004, 26:294-298.

102. Naimi TS, Brewer RD, Mokdad A, Denny C, Serdula MK, Marks JS: Binge drinking among US adults. JAMA 2003, 289:70-75.

103. Baan R, Straif K, Grosse Y, Secretan B, El Ghissassi F, Bouvard V, Alteri A, Cogliano V, on behalf of the WHO International Agency for Research on Cancer Monograph Working Group: Carcinogenicity of alcoholic beverages. Lancet Oncol 2007, 8:292-293.

104. Babor T, Caetano R, Casswell S, Edwards G, Giesbrecht N, Graham K, Grube J, Gruenewald P, Hill L, Holder H, Homel R, Livingston M, Osterberg E, Rehm J, Room R, Rossow I: Alcohol: No Ordinary Commodity. Research and Public Policy. 2nd edition. Oxford: Oxford University Press; 2010.

105. Room R, Babor T, Rehm J: Alcohol and public health: a review. Lancet 2005, 365:519-530.

doi:10.1186/s12916-014-0182-6

Cite this article as: Roerecke and Rehm: Alcohol consumption, drinking patterns, and ischemic heart disease: a narrative review of meta-analyses and a systematic review and meta-analysis of the impact of heavy drinking occasions on risk for moderate drinkers. BMC Medicine 2014 12:182.

\section{Submit your next manuscript to BioMed Central and take full advantage of:}

- Convenient online submission

- Thorough peer review

- No space constraints or color figure charges

- Immediate publication on acceptance

- Inclusion in PubMed, CAS, Scopus and Google Scholar

- Research which is freely available for redistribution 